\title{
ANALISIS EFISIENSI TEKNIS USAHATANI PADI SAWAH DI DESA CIGANJENG KECAMATAN PADAHERANG KABUPATEN PANGANDARAN
}

\section{ANALYSIS OF TECHNICAL EFFICIENCY OF RICE FARMING IN CIGANJENG VILLAGE, PADAHERANG DISTRICT, PANGANDARAN REGENCY}

\author{
ANGGITA APRIANTI ${ }^{1}$, TRISNA INSAN NOOR ${ }^{2}$, \\ AGUS YUNIAWAN ISYANTO ${ }^{1}$ \\ ${ }^{1}$ Fakultas Pertanian, Universitas Galuh \\ ${ }^{2}$ Fakultas Pertanian, Universitas Padjadjaran \\ *E-mail: anggitaaprianti63@gmail.com
}

\begin{abstract}
ABSTRAK
Penelitian bertujuan untuk mengetahui: (1) Faktor-faktor yang berpengaruh terhadap produksi usahatani padi sawah, (2) Tingkat efisiensi teknis yang dicapai pada usahatani padi sawah, dan (3) Faktor-faktor yang berpengaruh terhadap efisiensi teknis usahatani padi sawah. Penelitian ini menggunakan metode survey. Ukuran sampel sebanyak 39 orang ditentukan dengan menggunakan rumus Slovin. Tujuan penelitin nomor (1) dan (2) dianalisis dengan menggunakan fungsi produksi frontier stokhastik dimana pendugaan parameter dilakukanndengan menggunakan Front41. Tujuan penelitian (3) dianalisis dengan menggunakan regresi linier berganda dimana pendugaan parameter dilakukann dengan menggunakan SPSS versi 16. Hasil penelitian menunjukkan: (1) Faktor-faktor yang berpengaruh signifikan terhadap produksi padi sawah adalah luas lahan, pestisida, dan tenaga kerja. Sedangkan benih dan pupuk tidak berpengaruh signifikan, (2) Tingkat efisiensi yang dicapai rata-rata 0,85, dengan tingkat efisiensi minimum 0,58 dan maksimum 0,97, (3) Faktor-faktor yang berpengaruh terhadap efisiensi teknis pada usahatani padi sawah adalah pendidikan, pengalaman bertani, dan jumlah tanggungan keluarga, sedangkan umur tidak berpengaruh signifikan.
\end{abstract}

Kata Kunci: padi sawah, efisiensi teknis, produksi

\begin{abstract}
The research aims to determine: (1) The factors that influence the production of lowland rice farming, (2) The level of technical efficiency achieved in lowland rice farming, and (3) The factors that affect the technical efficiency of lowland rice farming. This study used a survey method. The sample size of 39 people was determined using the Slovin formula. The research objectives number (1) and (2) were analyzed using the stochastic frontier production function where the parameter estimation was carried out using Front41. The research objective (3) was analyzed using multiple linear regression where the estimation of parameters was carried out using SPSS version 16. The results showed: (1) The factors that significantly influence lowland rice production are land area, pesticides, and labor. While seeds and fertilizers did not have a significant effect, (2) The level of efficiency achieved was on average 0.85, with a minimum efficiency level of 0.58 and a maximum of 0.97, (3) Factors that had an effect on technical efficiency in lowland rice farming education, farming experience, and number of family dependents, while age did not have a significant effect.
\end{abstract}

Keywords: lowland rice, technical efficiency, production

\section{PENDAHULUAN}

Padi termasuk ke dalam komoditas pangan yang strategis untuk terus dikembangkan di Indonesia. Hal ini dikarenakan beras masih menjadi bahan 
makanan utama yang mendominasi pola makan masyarakat Indonesia.

Menurut Laksmi, dkk. (2012), faktor teknis dan faktor non teknis menjadi faktor penentu petani dalam menggunakan tenaga kerja efektif, pupuk dan obat-obatan sehingga menentukan tingkat produktivitas dan produksi usahatani padi sawah secara simultan. Upaya peningkatan produksi padi menjadi sangat penting seiring dengan bertambahnnya jumlah penduduk dan industri pangan.

Menurut Bradzik (2006), terdapat berbagai cara untuk meningkatkan produksi, yaitu dengan melakukan penambahan luas lahan (eksentifikasi), membuat inovasi teknologi baru, mengoptimalkan penggunaan lahan (intensifikasi), dan meningkatan efisiensi teknis melalui penggunaan sumberdaya yang ada. Peningkatan produksi melalui efisiensi teknis menjadi relevan untuk dilakukan saat ini, melihat bahwa untuk meningkatkan produktivitas saat ini tidak memungkinkan melalui perluasan lahan dan dalam jangka pendek adopsi teknologi sulit untuk dilakukan.

Produksi padi Kabupaten Pangandaran tahun 2018 berada pada urutan ke 16 dari 27 kabupaten atau kota yang ada di Provinsi Jawa Barat dengan produksi sebesar 205.986 ton GKG (BPS,
2018). Produksi terbesar dihasilkan oleh Kecamatan Padaherang sebesar 43.338,03 $\mathrm{kg}$, namun produktivitasnya masih rendah dibandingkan dengan kecamatan lain yaitu 61,77 kw/ha (Dinas Pertanian Kabupaten Pangandaran, 2019). Kecamatan Padaherang memiliki luas lahan paling luas yaitu 3.670 ha (BPP Kecamatan Padaherang, 2019), tersebar di 14 desa salah satunya adalah Desa Ciganjeng. Luas panen Desa Ciganjeng mengalami perbedaan yang signifikan tiap musim tanamnya karena terdapat rawa seluas 140 ha sehingga pada musim tanam I luas panen yang diusahakan hanya seluas 278 ha, hal tersebut mengakibatkan kurang optimalnya produksi yang dihasilkan. Turun naiknya luas panen, produksi, dan rata-rata produktivitasnya dipengaruhi oleh faktor-faktor produksi serta alam. Peningkatan efisiensi teknis dengan mengelola sumberdaya yang ada diharapkan mampu meningkatkan produktivitas dan produksi usahatani padi sawah sehingga petani dapat mengoptimalkan usahatani padi sawah di Desa Ciganjeng.

Berdasarkan uraian tersebut, maka penelitian ini bertujuan untuk mengetahui: (1) Faktor-faktor yang berpengaruh terhadap produksi usahatani padi sawah di Desa Ciganjeng Kecamatan Padaherang 
Kabupaten Pangandaran, (2) Tingkat efisiensi teknis yang dicapai pada usahatani padi sawah di Desa Ciganjeng Kecamatan Padaherang Kabupaten Pangandaran, dan (3) Faktor-faktor yang berpengaruh terhadap efisiensi teknis usahatani padi sawah di Desa Ciganjeng Kecamatan Padaherang Kabupaten Pangandaran.

\section{METODE PENELITIAN}

Penelitian dilaksanakan dengan menggunakan metode survey. Menurut Zikmund (1997), metode survey adalah suatu metode dalam penelitian yang mengumoulkan informasi dari beberapa sampel. Populasi penelitian sebanyak 318 petani, dan menentukan sampel penelitian dengan menggunakan rumus Slovin dengan error margin $15 \%$ sehingga ukuran sampel sebanyak 39 petani. Data yang digunakan adalah data primer yang diperoleh melalui hasil wawancara dengan petani dan data sekunder yang diperoleh dari instansi terkait juga berbagai literatur.

Variabel-variabel dalam penelitian ini adalah:

1. Efisiensi teknis merujuk pada hubungan input dan output, bagaimana petani memilih kombinasi input yang digunakan melalui kemampuan manajerial petani.
2. Variabel terikat: Produksi (Y) adalah jumlah produksi padi yang dihasilkan, dan dinyatakan dalam satuan kwintal (kw).

3. Variabel bebas: faktor-faktor yang mempengaruhi produksi.

a. Lahan $\left(\mathrm{X}_{1}\right)$, adalah luas lahan garapan yang diusahakan dalam usahatani padi sawah, dan dinyatakan dalam satuan hektar (ha).

b. Benih $\left(X_{2}\right)$ adalah jumlah penggunaan benih pada usahatani padi sawah, dan dinyatakan dalam satuan kilogram $(\mathrm{kg})$.

c. Pupuk $\left(\mathrm{X}_{3}\right)$, adalah jumlah penggunaan pupuk pada usahatani padi sawah dan dinyatakan dalam satuan kilogram $(\mathrm{kg})$.

d. Pestisida $\left(\mathrm{X}_{4}\right)$, adalah jumlah pestisida yang digunakan pada usahatani padi sawah dan dinyatakan dalam satuan liter (ltr).

e. Tenaga kerja $\left(\mathrm{X}_{5}\right)$ adalah jumlah tenaga kerja yang digunakan, dan dinyatakan dalam jumlah orang kerja (orang).

4. Faktor-faktor yang mempengaruhi efisiensi teknis.

- Variabel terikat: efisiensi teknis

- Variabel bebas: faktor-faktor yang mempengaruhi efisiensi teknis, yaitu 
karakteristik sosial ekonomi petani yang terdiri atas:

a. Umur $\left(\mathrm{X}_{1}\right)$, adalah umur petani padi sawah. dan diukur dalam satuan tahun (tahun).

b. Pendidikan $\left(\mathrm{X}_{2}\right)$, adalah pendidikan formal yang ditempuh oleh petani padi sawah, dan diukur dalam satuan tahun (tahun).

c. Pengalaman bertani $\left(\mathrm{X}_{3}\right)$, adalah lamanya pengalaman petani dalam usahatani padi sawah, dan diukur dalam satuan tahun (tahun).

d. Jumlah tanggungan keluarga $\left(\mathrm{X}_{4}\right)$, adalah banyaknya anggota keluarga petani padi sawah, dan diukur dalam satuan orang (orang).

Analisis data mengunakan fungsi produksi Cobb-douglas dengan pendekatan fungsi produksi stochastic frontier untuk mengestimasi efisiensi teknis, serta mengetahui faktor-faktor yang mempengaruhi produksi usahatani padi. Menggunakan model persamaan sebagai berikut:

$$
\begin{gathered}
\operatorname{Ln} Y=\ln \beta_{0}+\beta_{1} \ln X_{1}+\beta_{2} \ln X_{2}+\beta_{3} \ln X_{3}+ \\
\beta_{4} \ln X_{4}+\beta_{5} \ln X_{5}+(v i-u i)
\end{gathered}
$$

Keterangan:

$\mathrm{Y}=$ Produksi padi sawah $(\mathrm{kg})$

$\beta=$ Koefisien regresi

$\mathrm{X}_{1}=$ Lahan (ha)

$\mathrm{X}_{2}=$ Benih $(\mathrm{kg})$

$\mathrm{X}_{3}=$ Pupuk $(\mathrm{kg})$

$\mathrm{X}_{4}=$ Pestisida (liter)
$\mathrm{X}_{5}=$ Tenaga kerja (orang)

vi - ui $=$ error term (ui) efek inefisiensi dalam model.

Nilai koefisien regresi yang diharapkan: $\beta 1, \beta 2, \beta 3, \beta 4, \beta 5>0$ dan $\rho 1>0$ Untuk mengukur efisiensi teknis petani ke-i digunakan nilai harapan dari (ui) yang dinyatakan dalam rasio sebagai berikut :

$$
\boldsymbol{T} \boldsymbol{E}_{\boldsymbol{i}}=\frac{y_{\mathrm{i}}}{\exp \left(x_{\mathrm{i}} \beta\right)}=\frac{\exp \left(x_{\mathrm{i}} \beta-u_{\mathrm{i}}\right)}{\exp \left(x_{\mathrm{i}} \beta\right)}=\exp -u_{\mathrm{i}}
$$

Faktor-faktor yang berpengaruh terhadap efisiensi teknis dianalisis dengan menggunakan analisis linier berganda dengan pendugaan parameter koefisien regresi dilakukan dengan menggunakan programasi SPSS versi 16. Menggunakan model persamaan sebagai berikut :

$$
\mathrm{Y}=\mathrm{b} 0+\mathrm{b} 1 \mathrm{X} 1+\mathrm{b} 2 \mathrm{X} 2+\mathrm{b} 3 \mathrm{X} 3+\mathrm{b} 4 \mathrm{X} 4
$$

\section{Dimana:}

$$
\begin{aligned}
\mathrm{Y} & =\text { Efisiensi teknis } \\
\mathrm{b} & =\text { Koefisien regresi } \\
\mathrm{X} 1 & =\text { Umur (tahun) } \\
\mathrm{X} 2 & =\text { Pendidikan (tahun) } \\
\mathrm{X} 3= & \text { Pengalaman (tahun) } \\
\mathrm{X} 4= & \text { Jumlah Tanggungan Keluarga } \\
& \text { (orang) }
\end{aligned}
$$

\section{HASIL DAN PEMBAHASAN}

Faktor-faktor yang Berpengaruh

\section{Terhadap Produksi}


Faktor-faktor produksi yang diidentifikasi mempengaruhi produksi usahatani padi sawah di daerah penelitian adalah luas lahan, benih, pupuk, pestisida, dan tenaga kerja. Pendugaan model fungsi produksi stochastic frontier melalui pendekatan Maximum Likelihood Estimation (MLE) terdapat pada Tabel 1.

Tabel 1. Pendugaan Model Fungsi Produksi dengan Menggunakan Metode MLE pada Usahatani Padi Sawah

\begin{tabular}{lcrrr}
\hline \multicolumn{1}{c}{ Variabel } & Kode & Koefisien & Standar Error & t-ratio \\
\hline Intersep & $\beta_{0}$ & $-1,5570$ & 3,6851 & $-0,4225$ \\
Luas lahan $\left(\mathrm{X}_{1}\right)$ & $\beta_{1}$ & 0,8516 & 0,1789 & $4,7588^{*}$ \\
Benih $\left(\mathrm{X}_{2}\right)$ & $\beta_{2}$ & $-0,1387$ & 0,1805 & $-0,7668$ \\
Pupuk $\left(\mathrm{X}_{3}\right)$ & $\beta_{3}$ & $-0,1672$ & 0,1290 & $-1,2995$ \\
Pestisida $\left(\mathrm{X}_{4}\right)$ & $\beta_{4}$ & 0,1298 & 0,0548 & $2,3672^{* *}$ \\
Tenaga Kerja $\left(\mathrm{X}_{5}\right)$ & $\beta_{5}$ & 3,3208 & 1,1267 & $2,9474^{*}$ \\
\hline Sigma-squared & $\sigma^{2}$ & 0,0520 & 0,0171 & $3,0367^{*}$ \\
Gamma & $\Upsilon$ & 0,9222 & 0,0812 & $11,3534^{*}$ \\
Log likelihood function & & 21,6327 & & \\
LR Test & & $4,2941^{*}$ & & \\
\hline
\end{tabular}

Sumber: Data olahan primer, 2020

Keterangan: *, ** nyata pada $\alpha=1 \%(2,7333), 5 \%(2,0345)$

Secara matematis hasil fungsi produksi pada usahatani padi sawah dapat ditulis sebagai berikut :

$$
\begin{gathered}
\operatorname{Ln} \mathrm{Y}=-1,5570+0,8516 \operatorname{Ln} X_{1}-0,1387 \\
\operatorname{Ln} X_{2}-0,1672 \operatorname{Ln} X_{3}+0,1298 \operatorname{Ln} X_{4} \\
+3,3208 \operatorname{Ln} X_{5}+(\mathrm{vi}-\mathrm{ui})
\end{gathered}
$$

Pada tabel 1 dapat dilihat bahwa variabel yang berpengaruh signifikan adalah luas lahan, pestisida dan tenaga kerja. Hasil tersebut diperoleh dari nilai $t$ hitung > nilai t tabel. Variabel benih dan pupuk tidak berpengaruh signifikan terhadap hasil produksi karena nilai $\mathrm{t}$ hitung lebih kecil daripada nilai t Tabel.

Luas lahan memiliki elastisitas produksi sebesar 0,8516 (nyata pada $\alpha=$ 0,01). Nilai koefisien bertanda positif pada luas lahan berarti bahwa penambahan 1 persen luas lahan akan memberikan peningkatan produksi padi sebesar $0,8516 \%$ di mana faktor lain dianggap konstan dan diketahui bahwa nilai t hitung untuk variabel luas lahan sebesar 4,7588 lebih besar dari t Tabel 2,7333 ini artinya variabel luas lahan memiliki pengaruh signifikan pada produksi padi sawah. Hal tersebut sesuai dengan kondisi di lapangan yang menunjukkan bahwa luas lahan rata-rata yang digunakan masih tergolong sempit < 0.5 . variabel luas lahan memiliki pengaruh signifikan pada produksi sejalan dengan penelitian Tien (2011) pada usahatani padi, Maganga (2012) pada usahatani kentang. Rivanda dkk (2015) yang menyatakan bahwa faktor produksi yang berpengaruh besar dan nyata terhadap 
produksi padi sawah adalah luas lahan garapan.

Variabel pestisida memiliki elastisitas produksi sebesar 0,1298 (nyata pada $\alpha=0,05)$. Nilai koefisien pestisida yang bertanda positif ini berarti bahwa penambahan 1 persen pestisida akan memberikan peningkatan produksi padi sebesar $0,1298 \%$ di mana faktor lain dianggap konstan dan diketahui bahwa nilai $\mathrm{t}$ hitung untuk variabel pestisida sebesar 2,3672 lebih besar dari t Tabel 2,0345 ini artinya variabel pestisida berpengaruh signifikan terhadap produksi padi sawah.

Variabel tenaga kerja memiliki elastisitas produksi sebesar 3,3208 (nyata pada $\alpha=0,01)$. Nilai elastisitas tenaga kerja diantara variabel lainnya memiliki nilai yang paling tinggi. Hal tersebut menunjukkan bahwa tenaga kerja bisa lebih di fokuskan dalam meningkatan produksi padi sawah. Nilai koefisien tenaga kerja yang bertanda positif ini berarti bahwa penambahan 1 persen tenaga kerja akan memberikan peningkatan produksi padi sebesar $3,3208 \%$ di mana faktor lain dianggap konstan dan diketahui bahwa nilai t hitung untuk variabel tenaga kerja sebesar 2,9474 lebih besar dari t Tabel 2,7333 ini artinya variabel tenaga kerja berpengaruh signifikan terhadap produksi padi sawah. Hasil tersebut sejalan dengan penelitian Kurniawan (2012). Menurut Rivanda dkk (2015) sumber daya tenaga kerja yang memadai dan memiliki keterampilan serta kemampuan manajerial yang baik sangat menentukan berbagai keputusan dalam kegiatan usahatani sehingga menjadikan usahatani yang mereka jalankan menjadi lebih baik.

Variabel benih tidak berpengaruh signifikan, nilai koefisien benih yang bertanda negatif ini berarti bahwa pengurangan 1 persen benih akan memberikan peningkatan produksi padi sebesar 0,1387 persen. Koefisien benih yang bertanda negatif juga menunjukkan penggunaan benih sudah melebihi yang dianjurkan. Hal tersebut sesuai dengan kondisi di lapangan dimana petani pada saat proses penyemaian biasanya menggunkan benih lebih, hal tersebut dilakukan untuk mengantisipasi bibit yang mati pada saat penanaman. Hasil tersebut sejalan dengan penelitian Putri (2010). Variabel pupuk tidak berpengaruh signifikan, nilai koefisien menunjukkan tanda negatif ini berarti bahwa dengan mengurangi 1 persen pupuk akan memberikan peningkatkan produksi padi sebesar 0.1656 persen. Hal tersebut sejalan dengan penelitian Yusuf (2015). 
Hasil penelitian menunjukkan bahwa faktor-faktor yang berpengaruhi secara signifikan terhadap produksi pada usahatani padi sawah di Desa Ciganjeng Kecamatan Padaherang Kabupaten Pangandaran adalah luas lahan, pestisida dan tenaga kerja. Sedangkan benih dan pupuk tidak memberikan pengaruh signifikan pada produksi padi sawah. Petani dapat meningkatkan produksinya dengan cara menambah lahan, menggunakan benih unggul, mengurangi penggunaan pupuk, memperhatikan waktu penggunaan pestisida, serta meningkatkan keterampilan dan kemampuan tenaga kerja.

\section{Analisis Efisiensi Teknis Usahatani Padi} Sawah

Efisiensi teknis usahatani padi sawah dianalisis menggunakan pendekatan fungsi produksi stochastic frontier dengan metode estimasi Maximum Likelihood Estimate (MLE) dengan program frontier 4.1. Dengan metode ini tingkat produksi yang dicapai dari potensi produksi yang mungkin dapat dicapai oleh petani akan diketahui. Menurut Coelli et al (1998) bahwa suatu usaha dikatakan efisien jika nilai indeks efisiensi teknis lebih dari 0,70. Hasil estimasi efisiensi teknis usahatani padi sawah terdapat pada Tabel 2 .

\begin{tabular}{lr}
\multicolumn{2}{c}{ Tabel 2. Distribusi Efisiensi Teknis } \\
\hline \multicolumn{1}{c}{ Interval } & Petani \\
\hline $0,51-0,60$ & 1 \\
$0,61-0,70$ & 4 \\
$0,71-0,80$ & 4 \\
$0,81-0,90$ & 18 \\
$0,91-1,00$ & 12 \\
\hline Jumlah & $\mathbf{3 9}$ \\
Rata-rata & $\mathbf{0 , 8 5}$ \\
Minimum & $\mathbf{0 , 5 8}$ \\
Maksimum & $\mathbf{0 , 9 7}$ \\
\hline
\end{tabular}

Sumber: Data olahan primer, 2020

Berdasarkan Tabel 2 diatas menunjukkan bahwa usahatani padi sawah telah efisiensi secara teknis. Hal tersebut dapat dilihat dari banyaknya petani padi sawah yang memiliki nilai efisiensi teknis lebih dari 0,70. Sebanyak 5 responden tingkat efisiensi teknisnya berada pada interval $0,31-0,70$. Sedangkan 34 orang petani responden telah efisien secara teknis dalam menjalankan usahatani padi sawah. Nilai rata-rata yang dicapai petani padi sawah 0,85 . Nilai efisiensi teknis terkecil sebesar 0,58 dan nilai efisiensi teknis terbesar 0,97. Rata-rata nilai efisiensi teknis petani padi sawah mencapai 0,85 persen dari produksi potensial yang dihasilkan dengan input yang dikorbankan menggunakan teknologi yang ada. Hal ini memberikan gambaran kepada petani untuk dapat meningkatkan produksinya sebesar 0,15 persen. Jika petani yang 
memiliki nilai capaian efisiensi teknis minimum ingin mencapai efisiensi teknis maksimum maka terdapat tantangan sebesar 0,39 persen.

\section{Faktor-faktor yang Berpengaruh}

\section{Terhadap Efisiensi Teknis}

Tingkat capaian efisiensi teknis dapat dipengaruhi oleh kemampuan manjerial petani dalam menjalankan usahataninya. Kemampuan manajerial petani berhubungan dengan karakteristik petani itu sendiri. Karakteritik petani yang diduga berpengaruh terhadap efisiensi teknis adalah umur, pendidikan, pengalaman bertani, dan jumlah tanggungan keluarga. Hasil estimasi faktor-faktor yang berpengaruh pada efisiensi teknis usahatani padi sawah terdapat pada Tabel 3 .

Tabel 3. Faktor-faktor yang Berpengaruh Terhadap Efisiensi Teknis

\begin{tabular}{lrrr}
\hline \multicolumn{1}{c}{ Variabel } & Koefisien & Standar Error & \multicolumn{1}{c}{ t-ratio } \\
\hline Intersep & $-1,113$ & 0,457 & $-2,435^{* *}$ \\
Umur $\left(\mathrm{X}_{1}\right)$ & 0,099 & 0,176 & 0,559 \\
Pendidikan $\left(\mathrm{X}_{2}\right)$ & $-0,180$ & 0,063 & $-2,859^{* *}$ \\
Pengalaman Bertani $\left(\mathrm{X}_{3}\right)$ & 0,300 & 0,067 & $4,509^{*}$ \\
Jumlah Tanggungan Keluarga $\left(\mathrm{X}_{4}\right)$ & 0,058 & 0,030 & $1,898^{* * *}$ \\
\hline F-hitung = 102,847* & & & \\
$\mathrm{R}^{2} \quad 0,924$ & & & \\
\hline
\end{tabular}

Sumber: Data olahan primer, 2020

Keterangan: *,***** signifikan pada $\alpha=1 \%(2,7284), 5 \%(2,0322), 10 *(1,6909)$

Hasil analisis menunjukkan nilai koefisien determinasi $\left(\mathrm{R}^{2}\right)$ sebesar 0,924 menunjukkan bahwa capaian nilai efisiensi teknis pada usahatani padi sawah dapat dijelaskan sebesar 92,4 oleh variabel yang terdapat dalam model, sedangkan sisanya sebesar 7,6\% dijelaskan oleh model lain. Nilai F-hitung sebesar 102,847 pada taraf nyata $0,01 \%$ menunjukkan variabel umur, pendidikan, pengalaman bertani, dan jumlah tanggungan keluarga secara simultan mempengaruhi efisiensi teknis. Variabel yang berpengaruh secara signifikan terhadap efisiensi teknis adalah pendidikan, pengalaman bertani dan jumlah tanggungan keluarga. Sedangkan variabel umur tidak berpengaruh secara signifikan terhadap efisiensi teknis. Secara matematis model efisiensi teknis dapat ditulis sebagai berikut:

$$
\begin{array}{rl}
Y=-1 & 113+0,099 X_{1}-0,180 X_{2}+0,300 X_{3} \\
& +0,058 X_{4}
\end{array}
$$

Tabel 3 menunjukkan bahwa nilai koefisien variabel pendidikan -0,180 dan berpengaruh signifikan pada $\alpha=0,05$. Nilai koefisien regresi pendidikan bertanda negatif menunjukkan bahwa variabel pendidikan menurunkan tingkat capaian efisiensi teknis. Hal tersebut terjadi karena tingkat pendidikan responden yang masih 
rendah. Rata-rata responden hanya menempuh pendidikan SD/Sederajat. Rendahnya tingkat pendidikan tersebut berpengaruh terhadap sikap petani dalam menerima inovasi dan adopsi teknologi.

Nilai koefisien regresi variabel pengalaman betani 0,300 dan berpengaruh signifikan pada $\alpha=0,01$. Nilai koefisien bertanda positif menunjukkan bahwa variabel pengalaman bertani dapat meningkatkan capaian efisiensi teknis. Hal tersebut terjadi karena semakin lamanya pengalaman bertani responden semakin bisa meminimalisir resiko karena sudah banyak pengalaman dalam usahatani padi sawah. Pengalaman betani yang dimiliki responden rata-rata 20 tahun.

Nilai koefisien regresi variabel jumlah tanggungan keluarga 0,058 dan berpengaruh signifikan pada $\alpha=0,10$. Tanda positif pada nilai koefisien jumlah tanggungan keluarga berarti bahwa variabel jumlah tanggungan keluarga dapat meningkatkan capaian efisiensi teknis. Hasil tersebut sesuai dengan kondisi dilapangan dimana jumlah tanggungan keluarga petani responden rata-rata 2 orang. Hal ini disebabkan karena rata-rata petani memiliki anak yang sudah besar atau tua, sehingga jumlah tanggungan keluarga tidak banyak karena mereka sudah banyak yang menikah dan bekerja.
Nilai koefisien regresi variabel umur petani 0,099 dan tidak memiliki pengaruh signifikan pada efisiensi teknis. Nilai koefisien umur bertanda positif tersebut berarti semakin usia petani bertambah akan meningkatkan tingkat efisiensi teknisnya. Hal tersebut sesuai dengan kondisi dilapangan karena petani responden berada pada usia produktif. Petani berusia produktif berarti sudah banyak memiliki pengalaman dalam usahataninya.

\section{KESIMPULAN DAN SARAN}

\section{Kesimpulan}

1. Luas lahan, pestisida dan tenaga kerja berpengaruh signifikan dan berkolerasi positif terhadap produksi usahatani padi sawah, sedangkan faktor-faktor produksi lainnya seperti benih dan pupuk tidak berpengaruh signifikan terhadap produksi usahatani padi sawah.

2. Tingkat efisiensi yang dicapai usahatani padi sawah masih rendah dengan rata-rata nilai indeks efisiensi teknis sebesar 0,85, dengan nilai minimun 0,58 dan maksimum 0,97.

3. Pendidikan, pengalaman bertani, dan jumlah tanggungan keluarga berpengaruh signifikan terhadap efisiensi teknis sedangkan umur tidak berpengaruh signifikan terhadap 
efisiensi teknis pada usahatani padi sawah.

\section{Saran}

Penggunaan benih dan pupuk disesuaikan dengan kebutuhan sehingga tidak berlebih dan bisa menghemat biaya usahatani. Perlu upaya peningkatan frekuensi penyuluhan tentang manajerial usahatani padi sawah, peningkatan keterampilan dan teknis budidaya yang lebih baik dan tepat sasaran.

\section{DAFTAR PUSTAKA}

Badan Pusat Statistik Indonesia. 2018. Luas Panen, Produksi dan Produktivitas Padi Sawah Provinsi Jawa Barat 2014-2018. Jakarta.

Badan Pusat Statistik Jawa Barat. 2018. Survei Kerangka Sampel Area (KSA). Bandung.

Battese, G.E. and Coelli, T.J. 1991. Frontier Production Functions, Technical Efficiency and Panel Data. With Application to Paddy Farmers in India. Journal of Productivity Analysis. 3:153-169.

Battese, G.E. and Coelli, T.J and Colby, T.C. 1995. Estimations of Frontier Production Functions and Efficiencies of Indian Farms Using Panel Data From ICRISAT'c Village Level Studies. Journal of Quantitative Economics. 5: 327-348.

BPP Kecamatan Padaherang. 2020. Luas Lahan Sawah Kecamatan Padaherang 2019. Padaherang. .2020. Produktivitas, Luas Panen, dan Produksi Tiap Musim Tanam I dan II Tahun 2019 Kecamatan Padaherang. Padaherang.
Brazdik, F. 2006. Non Parametric Analysis of Technical Efficieny: Factors Affecting Efficiency of West Java Farms. Economics Institute, Academy of Sciences of the Czech Republic. Boston (US).

Coelli, T.J. D.S.P. Rao and G.E. Battese. 1998. Introduction to Efficiency and Productivity Analysis. Kluwer Academic Plublisher. Boston.

Dinas Pertanian Kabupaten Pangandaran. 2018. Luas Panen, Produksi dan Produktivitas Padi Sawah di Kabupaten Pangandaran 2019. Pangandaran.

Kurniawan, A.Y. 2012. Faktor-Faktor Yang Mempengaruhi Efisiensi Teknis pada Usahatani Padi Lahan Pasang Surut di Kecamatan Ajir Muara Kabupaten Barito Kuala Kalimantan Selatan. Jurnal Agribisnis Pedesaan. 2(1):35-52.

Laksmi, N.M.A.C., Suamba, I.K., dan Ambarawati, I.G.A.A. 2012. Analisis Efisiensi Usahatani Padi Sawah (Studi Kasus di Subak Guama, Kecamatan Marga, Kabupaten Tabanan). E-Journal Agribisnis dan Agrowisata, 1(1): 34-44.

Maganga, A.M. 2012. Technical Efficiency and its Determinants in Irish Potato Production: Evidence From Dedza District, Central Malawi. American-Eurasian. Journal Agric \& Environ. Sci. 12 (2):192-197.

Putri, K. 2010. Pengaruh Beberapa Faktor Produksi Terhadap Produksi Padi di Lahan Pasang Surut Desa Ajir Serapat Muara dan Serapat Muara I Kecamatan Ajir Muara Kabupaten Barito Kuala. [Skripsi]. Fakultas Pertanian. Universitas Lambung Mangkurat. Banjarbaru.

Rivanda, D.R., Nahraeni. W., Yusdiarti. A. 2015. Analisis Efisiensi Teknis Usahatani Padi Sawah (Pendekatan 
Stochastic Frontier). Jurnal AgribiSains, 1(1):1-13.

Tien, T. 2011. Analisis Efisiensi Teknis Usahatani Padi Sawah Aplikasi Pertanian Organik (Studi Kasus di Desa Sumber Ngepoh Kecamatan Lawang) Kabupaten Malang MT 2009-2010. Jurnal El-Hayah. 1(4): 182-191.
Yusuf, M.N. 2015. Efisiensi Teknis Usahatani Padi Sawah (Studi Kasus pada Kelompok tani Raksa Bumi III Desa Sindangsari Kecamatan Kawali Kabupaten Ciamis). Mimbar Agribisnis, 1(1): 85-94.

Zikmund, W.G. 1997. Business Research Methods. Fifth Edition. New York: The Dryden Press Harcourt Brace Collage Publishe. 